\title{
The Effect of Isostatic Pressing on the Dielectric Properties of Screen Printed $\mathrm{Ba}_{0.5} \mathrm{Sr}_{0.5} \mathrm{TiO}_{3}$ Thick Films
}

\author{
Siwei Wang, ${ }^{1}$ Lingling Zhang, ${ }^{1}$ Jiwei Zhai, ${ }^{2}$ and Fanglin Chen ${ }^{1}$ \\ ${ }^{1}$ Department of Mechanical Engineering, University of South Carolina, Columbia, SC 29208, USA \\ ${ }^{2}$ Functional Materials Research Laboratory, Tongji University, Shanghai 200092, China
}

Correspondence should be addressed to Lingling Zhang; zhang257@email.sc.edu

Received 23 October 2012; Revised 28 February 2013; Accepted 12 March 2013

Academic Editor: Shaomin Liu

Copyright (C) 2013 Siwei Wang et al. This is an open access article distributed under the Creative Commons Attribution License, which permits unrestricted use, distribution, and reproduction in any medium, provided the original work is properly cited.

$\mathrm{Ba}_{0.5} \mathrm{Sr}_{0.5} \mathrm{TiO}_{3}$ thick films with $\mathrm{B}_{2} \mathrm{O}_{3}-\mathrm{Li}_{2} \mathrm{O}$ glass sintering aid were prepared by the screen printing method on $\mathrm{Al}_{2} \mathrm{O}_{3}$ substrates. A $200 \mathrm{MPa}$ isostatic pressure was applied to the films before sintering. After being sintered at $950^{\circ} \mathrm{C}$, lower porosity and denser microstructure was obtained compared with the films without isostatic pressing. The dielectric constant and dielectric loss were 238 and 0.0028 , respectively. A tunability of $61.7 \%$ was obtained for the isostatic pressed films, a $27.8 \%$ enhancement compared to unpressurized films. These results suggest that isostatic pressing is an effective way to prepare dielectric thick films with dense microstructure, low dielectric loss, and high tunability.

\section{Introduction}

Barium strontium titanate solid solutions $\left(\left(\mathrm{Ba}_{1-x} \mathrm{Sr}_{x}\right) \mathrm{TiO}_{3}\right.$, denote as BST) are well-known dielectric materials and have been widely investigated and applied in many areas such as multilayer ceramic capacitors, ferroelectric random access memories, and optical modulators [1-4]. Of note, their characteristic of high dielectric nonlinearity (i.e., exhibiting a large dielectric constant change under DC bias electric field) enables BST materials to be one of the most promising materials to realize the applications of tunable ceramic capacitors, dielectric filters, phase shifters, and other tunable microwave devices $[5,6]$. On approach to fabricating these devices, however, people find that BST bulk ceramics are not suitable for the field applications due to their size encumbrance, and also their relatively high dielectric constants (above 1500) are difficult to satisfy the impedance matching and high power requirement in microwave device designs which prefer lower dielectric constant values $\left(30<\varepsilon_{r}<1000\right)$ [7]. BST thin films (normally with thickness less than $1 \mu \mathrm{m}$ ) can have lower dielectric constant but still cannot be applied properly in electric functional devices because of their relatively inferior dielectric properties and long term stability issues. Compared with thin film technologies, thick film fabrications, with membrane thickness in microns ranges, such as tape casting and screen printing techniques are mature techniques and have been applied in the industry applications for many years $[8,9]$. BST thick films have steadily superior dielectric performances, bigger driving force, and higher compression strength. Further, compared with bulk ceramics, BST thick films not only have the appropriate lower dielectric constant, but also take the incomparable advantage in the use of low biasing voltages due to its relatively low film thickness. Taking one with another, BST thick films are believed to fill out the gap between bulk materials and thin films.

Many methods and techniques have been applied to prepare BST thick films, such as sol-gel, electrophoretic deposition, tape casting, and screen printing [8-11]. Of all the options, screen printing is a flexible, versatile, and simple technology. Owing to its several advantages such as readily obtained and cost effective apparatus, screen printing technology has now been widely adopted in the preparation of thick films in industry. In this paper, we adopted the screen printing method to prepare BST thick films. Since BST bulk ceramics need a high sintering temperature (over $1200^{\circ} \mathrm{C}$ ) for densification, for the preparation of BST thick films, usually high temperature substrates not reacting with BST materials are needed to support the thick films for 
the cosintering process. An alternative is to prepare low temperature-fired BST materials and thus can be screen printed on readily accessible low temperature substrates. Herein we prepared $5 \mathrm{wt} \% \mathrm{~B}$-Li glass added $\mathrm{Ba}_{0.5} \mathrm{Sr}_{0.5} \mathrm{TiO}_{3}$ powders to prepare BST thick films on $\mathrm{Al}_{2} \mathrm{O}_{3}$ substrates since the B-Li glass doped BST dense bulk ceramics can be sintered at $950^{\circ} \mathrm{C}$ [12]. To assist the densification process, we applied isostatic pressing treatment on the $\mathrm{BST}-\mathrm{Al}_{2} \mathrm{O}_{3}$ substrates before sintering. Although the isostatic pressing may improve densification for materials [13], its effect on the properties of $\mathrm{Al}_{2} \mathrm{O}_{3}$ supported BST thick film is unknown. The effect of isostatic pressing treatment on the structural and dielectric properties and capacitance-voltage characteristics of the BST thick films were thus investigated.

\section{Experimental}

The $\mathrm{Ba}_{0.5} \mathrm{Sr}_{0.5} \mathrm{TiO}_{3}$ powder was first prepared stoichiometrically with starting $\mathrm{BaTiO}_{3}$ and $\mathrm{SrTiO}_{3}$ powders $(99.9 \%$, both hydrothermally synthesized by Shandong Guoteng Materials Co. Ltd.). $\mathrm{BaTiO}_{3}$ and $\mathrm{SrTiO}_{3}$ were mixed homogeneously using alcohol and zirconia milling media for $24 \mathrm{~h}$. After drying, the mixture was calcined at $1100^{\circ} \mathrm{C}$ for $4 \mathrm{~h}$ in air and then grinded and sieved to obtain BST powder. $\mathrm{H}_{3} \mathrm{BO}_{3}$ and $\mathrm{Li}_{2} \mathrm{CO}_{3}$ were weighted stoichiometrically as sintering aid via the following reaction:

$$
\begin{aligned}
4 \mathrm{H}_{3} \mathrm{BO}_{3}+3 \mathrm{Li}_{2} \mathrm{CO}_{3} & \\
= & \left(2 \mathrm{~B}_{2} \mathrm{O}_{3}+3 \mathrm{Li}_{2} \mathrm{O}\right)+3 \mathrm{CO}_{2} \uparrow+6 \mathrm{H}_{2} \mathrm{O} \uparrow
\end{aligned}
$$

$\mathrm{H}_{3} \mathrm{BO}_{3}$ and $\mathrm{Li}_{2} \mathrm{CO}_{3}$ were mixed and sintered at $1100^{\circ} \mathrm{C}$ for $30 \mathrm{~min}$ and then quenched to form B-Li glass. The glass was grinded and sieved to form glass powders. In consideration of our previous results [12], $5 \mathrm{wt} \%$ content B-Li glass powder was added to the BST powder as sintering aid. The screen printing paste was prepared with the glass-added BST powder and organic slurry. The composition of the slurry is $m$ (ethyl cellulose) $: m$ (terpineol) $=1: 10$ and the weight proportion of the powders to the slurry is $1: 1 . \mathrm{Al}_{2} \mathrm{O}_{3}$ ceramic plates (purity 99\%) with $30 \times 30 \times 0.5 \mathrm{~mm}^{3}$ were used as the substrates. A commercial silver-palladium paste (Guangdong Fenghua Co. Ltd.) was screen printed and fired as the bottom electrode. Thick film paste was then screen printed on the bottom electrode and dried. Figure 1 shows the schematic of the thick film configuration. Some of the green films were pressed under an isostatic pressure of $200 \mathrm{MPa}$ for $5 \mathrm{~min}$ before sintering. All of the thick films were then sintered at a temperature of $950^{\circ} \mathrm{C}$ for $2 \mathrm{~h}$. The film thicknesses are measured by a thickness gauge (CH-1-ST, Shanghai Liuling, China). X-ray diffraction (XRD) (Rigaku, Japan) with $\mathrm{Cu} \mathrm{K} \alpha$ radiation was employed to characterize the phase structures. Scanning electron microscope (SEM) (JSM EMP-800) was utilized to characterize the microstructures of the thick films. The temperature dependence of the dielectric constant and loss tangent were measured using an LCR meter (HP 4284A, Agilent, Palo Alto, CA, USA). The tunability of thick film was measured at $10 \mathrm{kHz}$ and room temperature using a Keithley model 2410 electrometer coupled with a TH2613A LCR meter.

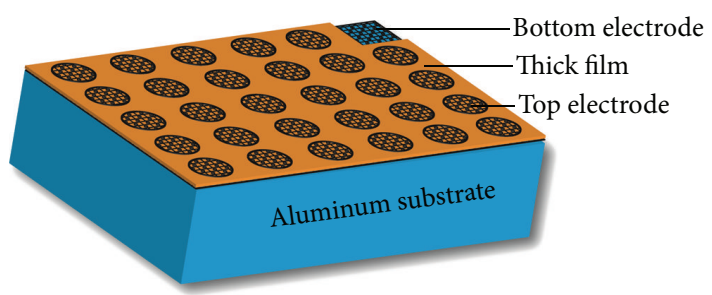

FIGURE 1: Schematic of the thick film configuration.

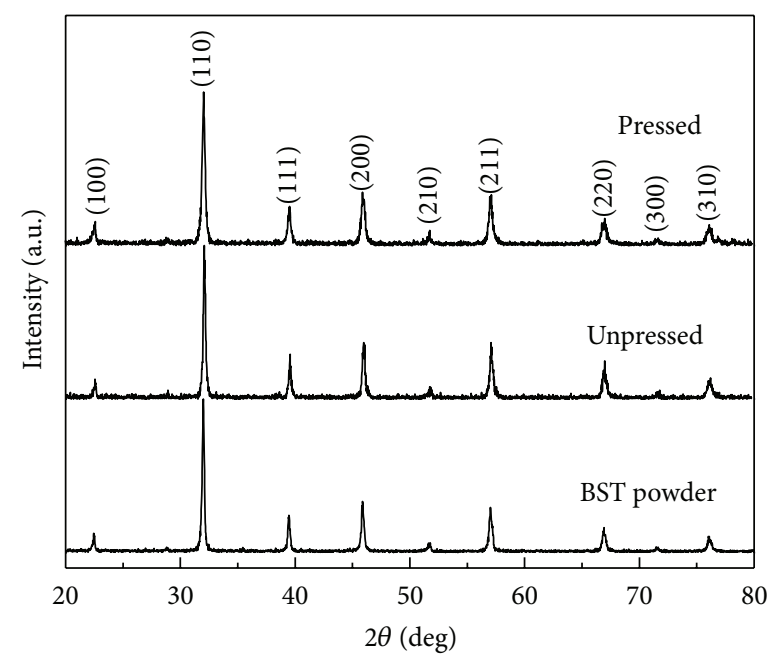

FIgURE 2: XRD patterns of $\mathrm{Ba}_{0.5} \mathrm{Sr}_{0.5} \mathrm{TiO}_{3}$ powder and $\mathrm{B}$-Li glass doped $\mathrm{Ba}_{0.5} \mathrm{Sr}_{0.5} \mathrm{TiO}_{3}$ thick films with isostatic pressing (denoted as pressed) and without isostatic pressing (denoted as unpressed).

\section{Results and Discussion}

Figure 2 shows the XRD patterns of the B-Li glass doped $\mathrm{Ba}_{0.5} \mathrm{Sr}_{0.5} \mathrm{TiO}_{3}$ calcined powder and thick films without isostatic pressing (unpressed) and with isostatic pressing (pressed) after being sintered at $950^{\circ} \mathrm{C}$ for $2 \mathrm{~h}$. All the diffraction peaks can be indexed to perovskite structured cubic phased $\mathrm{Ba}_{0.5} \mathrm{Sr}_{0.5} \mathrm{TiO}_{3}$ (space group Pm-3 m, PDF no. 39-1395) [14]. Both the powder and thick films are well crystallized with no preferred orientation and second phase. It can be seen that the addition of B-Li glass as well as the isostatic pressing treatment has no obvious impact on the crystallization of the thick films.

Figure 3 shows the microstructures of BST thick films after sintered at $950^{\circ} \mathrm{C}$ for $2 \mathrm{~h}$, with and without the isostatic pressing treatment. The SEM analysis reveals that the surface morphology of the thick film with the isostatic pressing treatment is notably different from the one without treatment. The thick film without isostatic pressing (shown in Figures 3(a1) and 3(a2)) shows a coarse surface, a porous and inhomogeneous microstructure. In contrast, the thick film with the isostatic pressing step (shown in Figures 3(b1) and 3(b2)) exhibits a smoother surface, more uniform and denser microstructure. Furthermore, for the isostatic pressed sample, larger grains are formed compared with the unpressed thick film where sphered small grains are 
TABLE 1: Thickness of the films in different steps with and without isostatic pressing.

\begin{tabular}{lccc}
\hline Thick film sample & Thickness of green film & Thickness after pressing & Thickness after sintering \\
\hline Unpressed & $25.5 \mu \mathrm{m}$ & - & $21 \mu \mathrm{m}$ \\
Pressed & $26 \mu \mathrm{m}$ & $21.5 \mu \mathrm{m}$ & $19.5 \mu \mathrm{m}$ \\
\hline
\end{tabular}

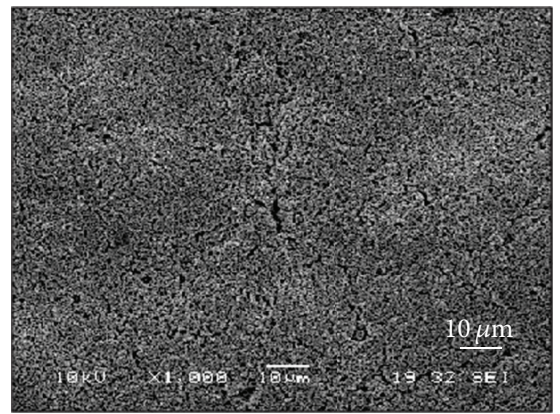

(a1)

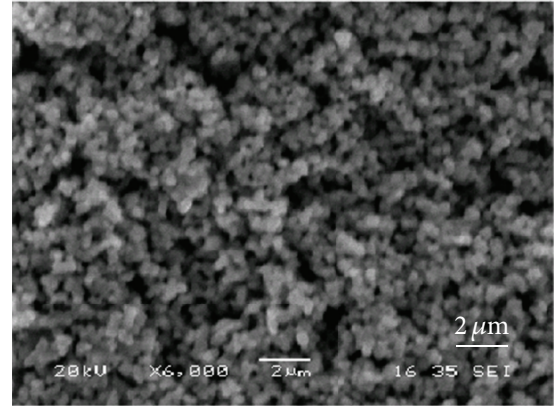

(a2)

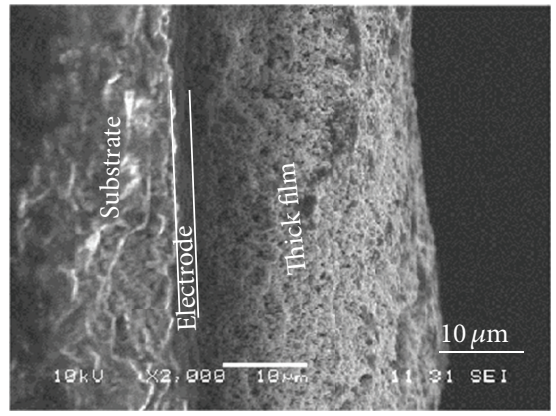

(a3)

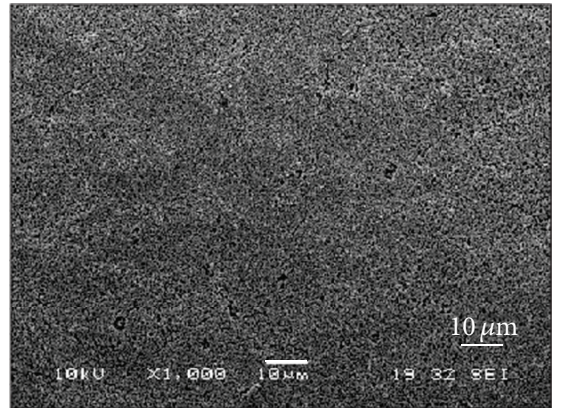

(b1)

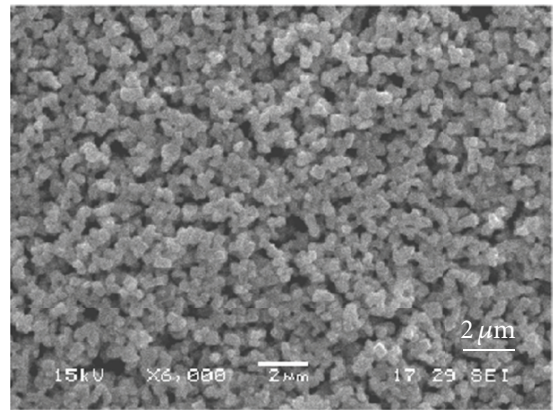

(b2)

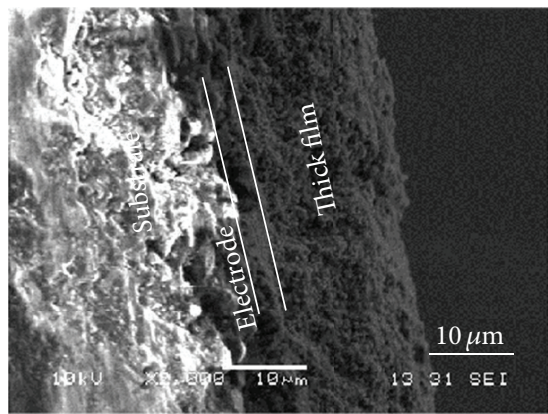

(b3)

FIgURE 3: SEM photographs of $\mathrm{Ba}_{0.5} \mathrm{Sr}_{0.5} \mathrm{TiO}_{3}$ thick films. (al-a3) without isostatic pressing treatment, (b1-b3) with isostatic pressing treatment, (a1, b1) surface morphologies, (a2, b2) expanded view of surface morphologies, and (a3, b3) cross-sectional images.

loosely distributed, which is an indication that the thick film with isostatic pressure shows better sinterability. The cross-sectional SEM pictures of the thick films are shown in Figures 3(a3) and 3(b3). Since the thick films are sintered at $950^{\circ} \mathrm{C}$, a temperature significantly lower than the diffusion temperature of barium into $\mathrm{Al}_{2} \mathrm{O}_{3}$ (above $1200^{\circ} \mathrm{C}[15,16]$ ), there is no reaction between the substrate and BST. Table 1 measures the thickness of thick films in different steps with and without the application of isostatic pressing treatment. It can be seen that the thick film after isostatic pressing shows thinner film thickness. The reduction of the thickness of the film with isostatic pressing from green film state to sintered state is about $25 \%$, compared to $17.6 \%$ for the film without treatment. This difference may be expected with the reason that with the application of isostatic pressing treatment, powders are more compactly contacted with each other and the effect of sintering aid is thus functioning better for the pressurized samples. The sintered film thus shows lower porosity and denser microstructure and the thickness was reduced at a large scale [13]. It is noted that due to the difference of thermal expansion coefficient between BST and $\mathrm{Al}_{2} \mathrm{O}_{3}$, the BST thick films we prepared are not fully 


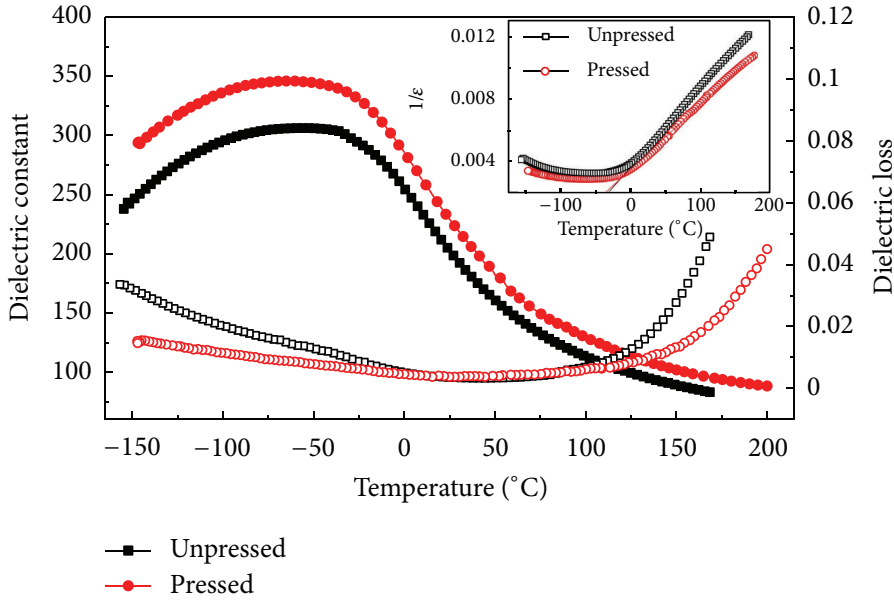

(a)

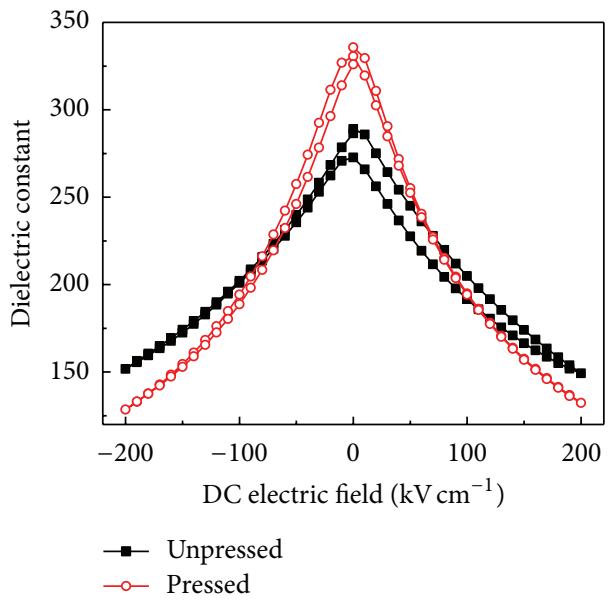

(b)

Figure 4: (a) Temperature dependence of dielectric constant and dielectric loss of $\mathrm{Ba}_{0.5} \mathrm{Sr}_{0.5} \mathrm{TiO}_{3}$ thick films with and without isostatic pressing; inset: the inverse dielectric constant $(1 / \varepsilon)$ as a function of temperature. The symbols: experimental data; the solid line: fitting to the Curie-Weiss law. (b) DC electric field dependence of thick films with and without isostatic pressing.

dense compared with bulk ceramics [12]. Although porous dielectric materials are hot research topics, it is out of our scope, and for a better sinterability of the BST thick films, besides the isostatic pressure, a proper substrate as well as an optimum sintering temperature is needed. It is also possible that the electrode may affect the properties of the thick film, while in our study, on the one hand, we use Pd-Ag electrode, with low sintering temperature of the electrodes, the diffusion of electrodes to the ceramic is suppressed and cannot be observed, and on the other hand, since the Unpressed and Pressed thick films both use the same electrode and share the same structure; the influence of electrodes should be similar; thus in our study, the influence of electrode on the ceramics is not considered.

The temperature dependence of dielectric constant and loss of the thick film with and without the application of isostatic pressing are presented in Figure 4(a). The dielectric peaks are suppressed and broadened compared with bulk BST [17]. The inverse dielectric constant $(1 / \varepsilon)$ as a function of temperature by using the Curie-Weiss equation has been plotted. Figure 4(a) inset shows the plots of inverse dielectric constant as a function of temperature. The solid lines are plotted by fitting the Curie-Weiss law [18]

$$
\frac{1}{1 / \varepsilon}=\left(T-T_{c}\right), \quad\left(T>T_{c}\right)
$$

The Curie temperature is thus estimated from the intercept of the fitted line with the temperature axis. The Curie temperatures are $-36.4^{\circ} \mathrm{C}$ and $-30.5^{\circ} \mathrm{C}$ for the films with and without isostatic pressing, respectively. The decrease of Curie temperature of the thick film with isostatic pressing treatment can be attributed to the strains introduced into the lattice at the onset of spontaneous polarization. The decreasing trend is in agreement with the results reported by Samara [19]. At $10 \mathrm{kHz}$ and room temperature, the dielectric constants of the films with and without treatment are 238 and 210, respectively, both of which are suitable for microwave device designs in quest of impedance matching and high power requirement [7]. The increase of the dielectric constant is also a reflection of more densified microstructure. A porous ceramic can be considered dual-phase system composed of bulk ceramic and air pores. Considering that the dielectric constant of air is around 1, less air pores will lead to higher dielectric constant [20]. The dielectric losses in the sample with isostatic pressing treatment are generally lower than unpressed one. At temperature ranging from room temperature to $100^{\circ} \mathrm{C}$, the dielectric losses are within the same lower scale for both unpressed and pressed samples. When the testing temperature goes higher $\left(>100^{\circ} \mathrm{C}\right)$ or lower $\left(<-50^{\circ} \mathrm{C}\right)$, the dielectric loss increases, which is not beneficial for applications. It is noted that the dielectric loss of the pressed sample has lower degree of increment. The dielectric loss is affected by many factors such as external frequency and temperature, internal structure and lattice defects such as grain boundaries, void and defects [21]. The dielectric properties of thick films are closely related to the microstructure of the dielectric layer and the grain size effect [8]. Denser microstructure with less external porosity is beneficial for lower dielectric loss. For the unpressed thick film, its porous microstructure and rough surface deteriorate the dielectric properties. At room temperature, the dielectric loss at $10 \mathrm{kHz}$ in the film after pressing is 0.0028 , compared with 0.0037 without pressing. Compared with a bulk BST material sintered at $1350^{\circ} \mathrm{C}$, with the dielectric constant above 1500 and dielectric loss in the range of 0.002 [20], the isostatic-pressure-treated screen printed BST thick films show prominent modification on dielectric constant while maintaining the low dielectric loss, which is suitable for microwave device designs.

The DC electric field dependence of the dielectric constant of the film with and without applying of isostatic pressing are presented in Figure 4(b). Considering the thickness 
TABLE 2: Comparison of dielectric properties for BST materials prepared by different methods.

\begin{tabular}{|c|c|c|c|c|c|}
\hline BST systems & $\begin{array}{c}\text { Sintering } \\
\text { temperature }\end{array}$ & $\begin{array}{c}\text { Dielectric } \\
\text { constant }\end{array}$ & $\begin{array}{l}\text { Dielectric } \\
\text { loss }\end{array}$ & Tunability & References \\
\hline $\begin{array}{l}\text { Thick film (screen printed, isostatic pressed, } \\
\text { B-Li sintering aid, } 19.5 \mu \mathrm{m} \text { ) }\end{array}$ & $950^{\circ} \mathrm{C}$ & 238 & 0.0028 & $61.7 \%\left(200 \mathrm{kV} \mathrm{cm}^{-1}\right)$ & Current work \\
\hline Thick film (screen printed, $20 \mu \mathrm{m}$ ) & $1200-1300^{\circ} \mathrm{C}$ & 200 & 0.0027 & $9 \%\left(20 \mathrm{kV} \mathrm{cm}^{-1}\right)$ & Su et al. [22] \\
\hline Thick film (nanosized, screen printed) & $1250^{\circ} \mathrm{C}$ & 180 & 0.02 & - & $\begin{array}{c}\text { Ditum and Button } \\
\text { [23] }\end{array}$ \\
\hline Thick film (screen printed, $\mathrm{PbO}$ sintering aid) & $850^{\circ} \mathrm{C}$ & - & - & $10 \%\left(20 \mathrm{kV} \mathrm{cm}^{-1}\right)$ & Zhang et al. [24] \\
\hline Bulk material (solid state reaction) & $1350^{\circ} \mathrm{C}$ & 2500 & 0.0008 & $22.7 \%\left(30 \mathrm{kV} \mathrm{cm}^{-1}\right)$ & Wang et al. [25] \\
\hline Porous bulk material (solid state reaction) & $1350^{\circ} \mathrm{C}$ & 990 & 0.002 & $19.6 \%\left(26 \mathrm{kV} \mathrm{cm}^{-1}\right)$ & Zhang et al. [20] \\
\hline Thin film (sol-gel, (100) oriented) & $1100^{\circ} \mathrm{C}$ & 2714 & 0.0215 & $51.9 \%\left(25.3 \mathrm{kV} \mathrm{cm}^{-1}\right)$ & Jain et al. [26] \\
\hline
\end{tabular}

of the films (about $20 \mu \mathrm{m}$ ), a relatively low bias voltage $(400 \mathrm{~V})$ can reach a relatively high electric field applied to the film $\left(200 \mathrm{kV} \mathrm{cm}^{-1}\right)$, which is a big advantage of thick films if considering normally applied electric field of less than $30 \mathrm{kV} \mathrm{cm}^{-1}$ for bulk ceramics. When the electric field is set to $200 \mathrm{kV} \mathrm{cm}^{-1}$, the tunability $\left(n=\left(\varepsilon_{r}(0)-\varepsilon_{r}(E)\right) / \varepsilon_{r}(0)\right)$ with the isostatic pressing treatment reaches $61.7 \%$, compared to $48.3 \%$ of the film without isostatic pressing. If we consider the thick films as composites of air and BST bulk materials, more pores would dilute the tunability of BST ceramics [20]. It is noted that the tunability for the thick film is more than 3 times larger than their peer bulk ceramics $[17,20]$. Table 2 compares in detail the tunability and the dielectric properties of the current work with reported publications. It can be seen that the isostatic pressed thick films obtained in this work possess combined properties of suitable low dielectric constant, low dielectric loss, and high tunability endured under high voltages, showing good enough film quality potentially applicable for the fabrication of tunable microwave thick film devices.

\section{Conclusions}

In summary, low-temperature-fired $\mathrm{Ba}_{0.5} \mathrm{Sr}_{0.5} \mathrm{TiO}_{3}$ thick films were prepared by screen printing method. Isostatic pressing treatment was introduced to the thick film preparation process before sintering. A thick film with more densified microstructure and uniform surface was obtained by the isostatic pressing treatment. Increased dielectric constant and lower dielectric loss can be obtained for the pressurized thick film. The tunability of the thick film after pressing reached $61.7 \%$, more advantageous for the fabrication of tunable advices. These results reveal that isostatic pressing treatment is an effective way to prepare denser screen printed thick films with lower dielectric loss and higher tunability for tunable dielectric and microwave devices.

\section{Acknowledgment}

The financial support of the Department of Energy Nuclear Energy University Program (NEUP) is gratefully acknowledged.

\section{References}

[1] H. Diamond, "Variation of permittivity with electric field in perovskite-like ferroelectrics," Journal of Applied Physics, vol. 32, no. 5, article 909, 7 pages, 1961.

[2] A. Feteira, D. C. Sinclair, I. M. Reaney, Y. Somiya, and M. T. Lanagan, "BaTiO 3 -based ceramics for tunable microwave applications," Journal of the American Ceramic Society, vol. 87, no. 6, pp. 1082-1087, 2004.

[3] K. Kageyama and J. Takahashi, "Tunable microwave properties of barium titanate-based ferroelectric glass-ceramics," Journal of the American Ceramic Society, vol. 87, no. 8, pp. 1602-1605, 2004.

[4] B. Su and T. W. Button, "Microstructure and dielectric properties of Mg-doped barium strontium titanate ceramics," Journal of Applied Physics, vol. 95, no. 3, article 1382, 4 pages, 2004.

[5] J. W. Zhai, T. F. Hung, and H. Chen, "Relaxor and nonlinear behaviors of $\mathrm{SrTiO}_{3} / \mathrm{BaTiO}_{3}$ multilayers derived by a sol-gel process," Applied Physics Letters, vol. 85, no. 11, article 2026, 3 pages, 2004.

[6] T. Maiti, R. Guo, and A. S. Bhalla, "Electric field dependent dielectric properties and high tunability of $\mathrm{BaZr}_{x} \mathrm{Ti}_{1-x} \mathrm{O}_{3}$ relaxor ferroelectrics," Applied Physics Letters, vol. 89, no. 12, Article ID 122909, 3 pages, 2006.

[7] E. A. Nenasheva, A. D. Kanareykin, N. F. Kartenko, A. I. Dedyk, and S. F. Karmanenko, "Ceramics materials based on (Ba, $\mathrm{Sr}) \mathrm{TiO}_{3}$ solid solutions for tunable microwave devices," Journal of Electroceramics, vol. 13, no. 1-3, pp. 235-238, 2004.

[8] B. D. Stojanovic, C. R. Foschini, V. Z. Pejovic, V. B. Pavlovic, and J. A. Varela, "Electrical properties of screen printed $\mathrm{BaTiO}_{3}$ thick films," Journal of the European Ceramic Society, vol. 24, no. 6, pp. 1467-1471, 2004.

[9] Z. Yuan, J. Liu, and J. Weaver, "Ferroelectric $\mathrm{BaTiO}_{3}$ thin films on Ni metal tapes using $\mathrm{NiO}$ as buffer layer," Applied Physics Letters, vol. 90, no. 20, Article ID 202901, 3 pages, 2007.

[10] H. B. Sharma and H. N. K. Sarma, "Electrical properties of solgel processed barium titanate films," Thin Solid Films, vol. 330, no. 2, pp. 178-182, 1998.

[11] J. L. Zhao, X. H. Wang, and L. T. Li, "Electrophoretic deposition of $\mathrm{BaTiO}_{3}$ films from aqueous suspensions," Materials Chemistry and Physics, vol. 99, no. 2-3, pp. 350-353, 2006.

[12] X. J. Chou, J. W. Zhai, J. Y. Sun, and X. Yao, "Dielectric properties of $\mathrm{B} \sim 2 \mathrm{O} \sim 3-\mathrm{Li} \sim 2 \mathrm{O}$ Co-Doped $\mathrm{Ba} \sim 0 \sim$. $6 \mathrm{Sr} \sim 0 \sim$. $4 \mathrm{TiO} \sim 3$ ceramic sintered at a low temperature," Journal of the Chinese Ceramic Society, vol. 35, part 2, pp. 149-153, 2007. 
[13] L. Zhang, J. Zhai, and X. Yao, "Dielectric properties of electrophoretically deposited and isothermally pressed $\mathrm{BaTiO}_{3}$ thick films," Journal of the American Ceramic Society, vol. 91, no. 6, pp. 2075-2077, 2008.

[14] L. L. Zhang, X. S. Wang, W. Yang, H. Liu, and X. Yao, "Structure and relaxor behavior of $\mathrm{BaTiO}_{3}-\mathrm{CaTiO}_{3}-\mathrm{SrTiO}_{3}$ ternary system ceramics," Journal of Applied Physics, vol. 104, no. 1, Article ID 014104, 5 pages, 2008.

[15] C. M. Ditum and T. W. Button, "Screen printed barium strontium titanate films for microwave applications," Journal of the European Ceramic Society, vol. 23, no. 14, pp. 2639-2697, 2003.

[16] T. Tick, J. Peräntie, H. Jantunen, and A. Uusimäki, "Screen printed low-sintering-temperature barium strontium titanate (BST) thick films," Journal of the European Ceramic Society, vol. 28, no. 4, pp. 837-842, 2008.

[17] S. W. Wang, J. W. Zhai, X. J. Chou, L. L. Zhang, and X. Yao, "Dielectric tunable properties of $\mathrm{Ba}_{0.6} \mathrm{Sr}_{0.4} \mathrm{TiO}_{3}-\mathrm{BaZn}_{6} \mathrm{Ti}_{6} \mathrm{O}_{19}$ microwave composite ceramics," Materials Chemistry and Physics, vol. 115, no. 1, pp. 200-203, 2009.

[18] X. G. Tang, K. H. Chew, and H. L. W. Chan, "Diffuse phase transition and dielectric tunability of $\mathrm{Ba}\left(\mathrm{Zr}_{y} \mathrm{Ti}_{1-y}\right) \mathrm{O}_{3}$ relaxor ferroelectric ceramics," Acta Materialia, vol. 52, no. 17, pp. 51775183, 2004.

[19] G. A. Samara, "Pressure and temperature dependences of the dielectric properties of the perovskites $\mathrm{BaTiO}_{3}$ and $\mathrm{SrTiO}_{3}$," Physical Review, vol. 151, no. 2, pp. 378-386, 1966.

[20] Y. Y. Zhang, G. S. Wang, T. Zeng, R. H. Liang, and X. L. Dong, "Electric field-dependent dielectric properties and high tunability of porous $\mathrm{Ba}_{0.5} \mathrm{Sr}_{0.5} \mathrm{TiO}_{3}$ ceramics," Journal of the American Ceramic Society, vol. 90, no. 4, pp. 1327-1330, 2007.

[21] H. Tamura, "Microwave dielectric losses caused by lattice defects," Journal of the European Ceramic Society, vol. 26, no. 10-11, pp. 1775-1780, 2006.

[22] B. Su, J. E. Holmes, C. Meggs, and T. W. Button, "Dielectric and microwave properties of barium strontium titanate (BST) thick films on alumina substrates," Journal of the European Ceramic Society, vol. 23, no. 14, pp. 2699-2703, 2003.

[23] C. M. Ditum and T. W. Button, "Screen printed barium strontium titanate films for microwave applications," Journal of the European Ceramic Society, vol. 23, no. 14, pp. 2693-2697, 2003.

[24] D. Zhang, W. Hu, C. Meggs et al., "Fabrication and characterisation of barium strontium titanate thick film device structures for microwave applications," Journal of the European Ceramic Society, vol. 27, no. 2-3, pp. 1047-1051, 2007.

[25] S. W. Wang, J. W. Zhai, X. J. Chou, and X. Yao, "Screen printing B-Li glass doped $\mathrm{Ba}_{0.5} \mathrm{Sr}_{0.5} \mathrm{TiO}_{3}$ thick film and its dielectric properties," Journal of Functional Materials, vol. 40, pp. 767-770, 2009.

[26] M. Jain, S. B. Majumder, R. S. Katiyar, and A. S. Bhalla, "Structural and dielectric properties of heterostructured BST thin films by sol-gel technique," Thin Solid Films, vol. 447-448, pp. 537-541, 2004. 

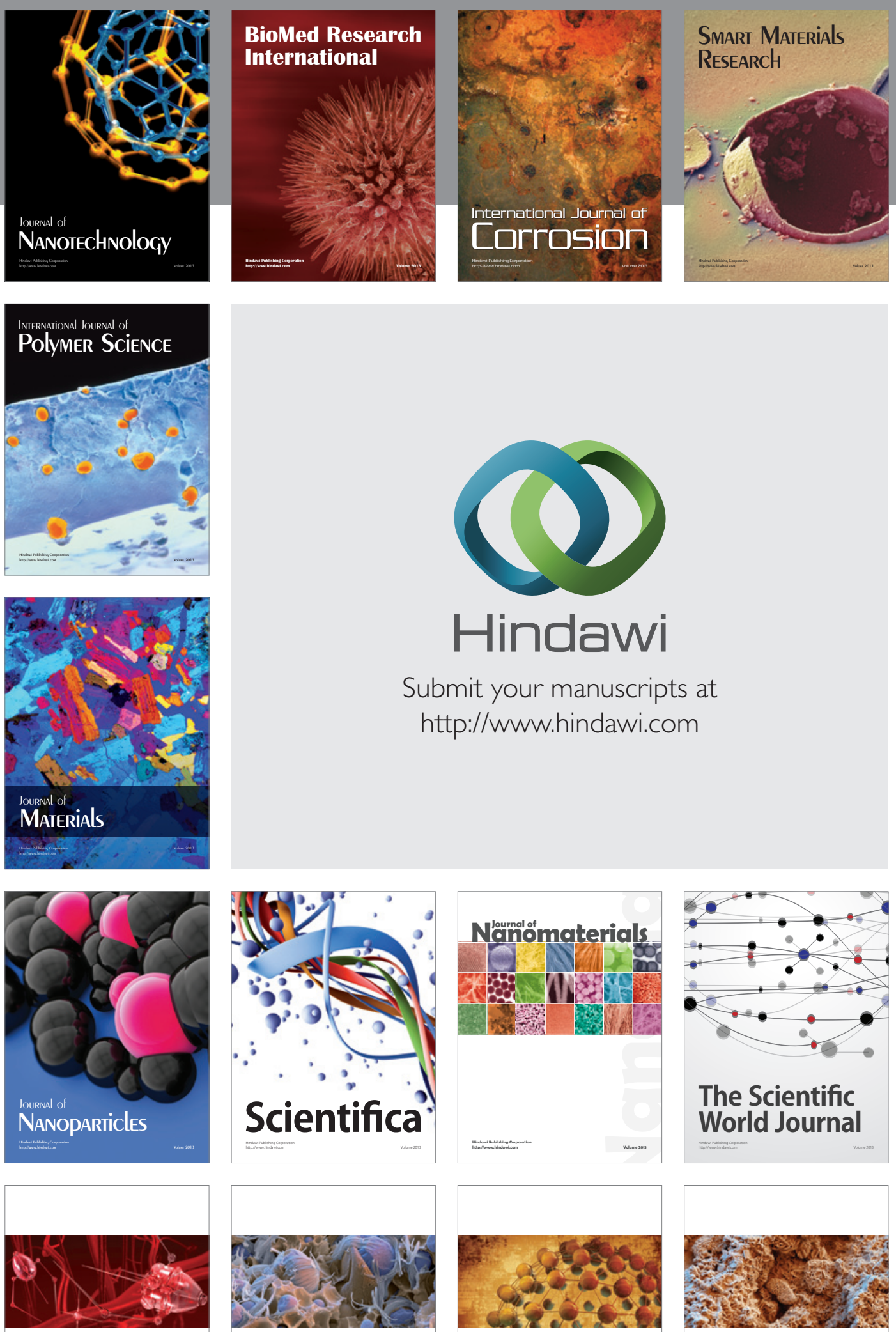

ISRN

Nanotechnology
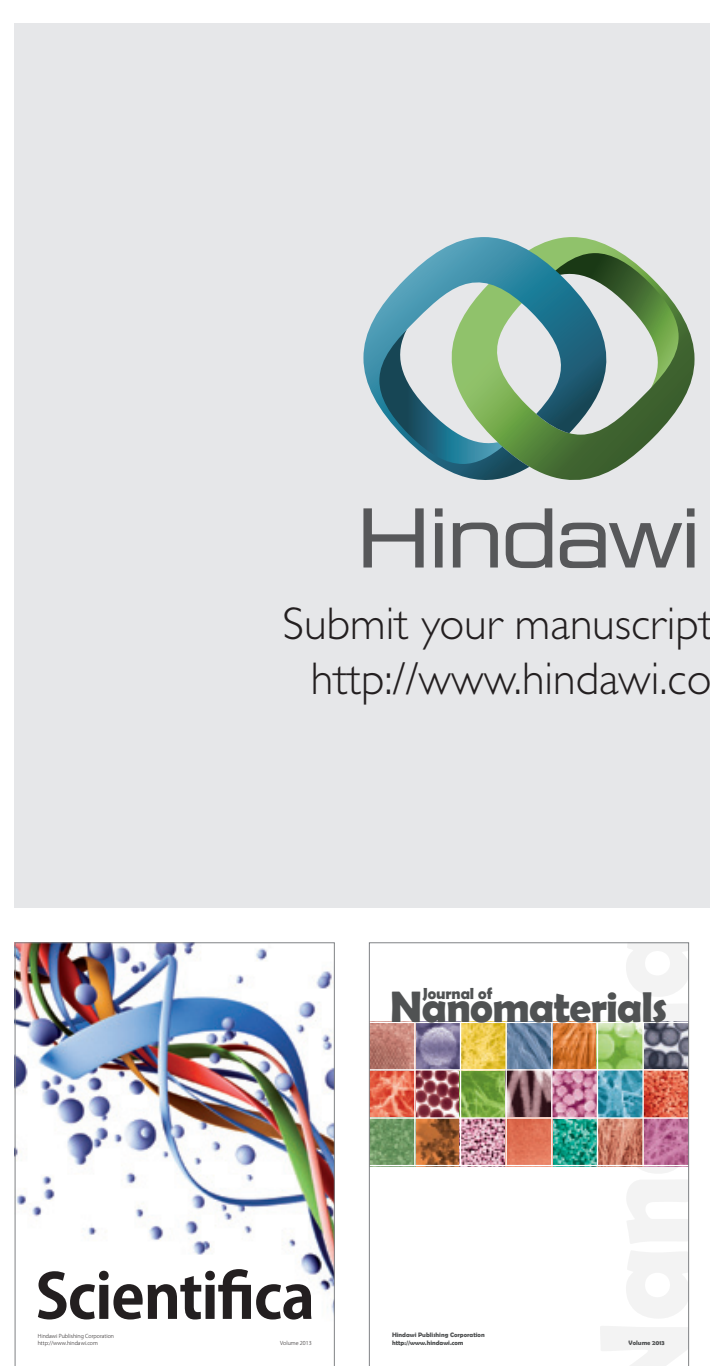

Submit your manuscripts at http://www.hindawi.com
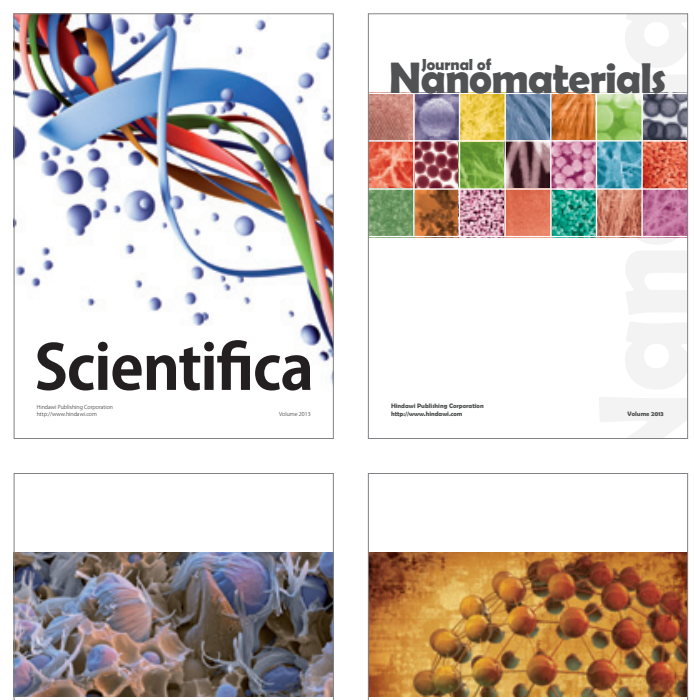

ISRN

Polymer Science

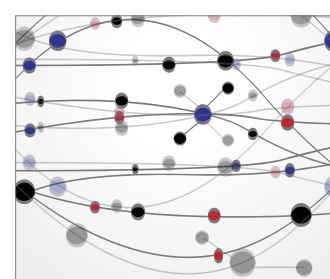

The Scientific World Journal

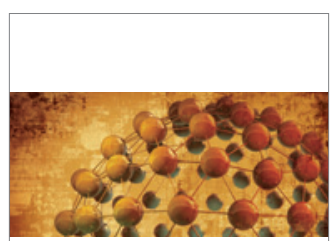

ISRN

Materials Science

\section{World Jounal}

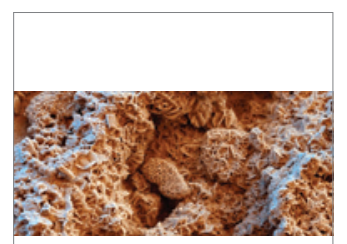

ISRN

Corrosion
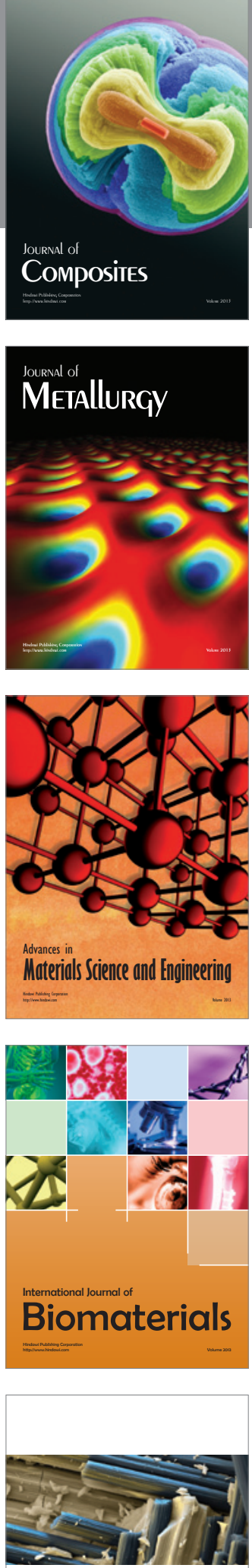

ISRN

Ceramics 